\section{Time-lapse zirconography: Imaging punctuated continental evolution}

\section{S.W. Parman ${ }^{1 *}$}

\section{Abstract}

doi: 10.7185/geochemlet.1505

The continental crust (CC) contains a 4.4 billion year record of Earth evolution (Armstrong 1991; Bowring and Housh, 1995; Wilde et al., 2001; Harrison et al., 2005; Hawkesworth et al, 2010; Condie and Kroener, 2013). Understanding its growth is central to a broad range of research, including the geodynamics of the planet's interior (O'Neill et al., 2007; Korenaga, 2013), the evolution of the atmosphere (Barley et al., 2005) and even the evolution of life itself (Lowe and Tice, 2007). The growth of the continents is a competition between rates of crustal production and destruction (Armstrong, 1991; Hawkesworth et al., 2010), but which of these dominates the CC record is debated. Here I examine a large database of detrital zircon U-Pb ages ( $\mathrm{n}>200,000$; Voice et al., 2011) as a function of the age of the sedimentary rock in which they are found. This provides snapshots of the Earth's CC age distribution through time; in essence, producing a time-lapse movie of CC evolution. The analysis strongly indicates that the growth of the CC was episodic

Received 12 March 2015 | Accepted 24 March 2015 | Published 8 May 2015

\section{Introduction}

Zircons found in sediments and sedimentary rocks (detrital zircons) are primary records of CC age distribution (Rino et al., 2004; Belousova et al., 2010; Hawkesworth et al., 2010; Condie et al., 2011; Voice et al., 2011). All global compilations of detrital zircon $\mathrm{U}-\mathrm{Pb}$ ages display peaks at 2.7, 1.9 and 1.2 Ga (Fig. 1; Rino et al., 2004; Belousova et al., 2010; Hawkesworth et al., 2010; Voice et al., 2011; Dhuime et al., 2012; Condie and Kroener, 2013). Smaller, less consistently observed peaks are observed around 3.3, 0.6 and $0.2 \mathrm{Ga}$. These peaks match peaks in other estimates of CC age distributions (Condie, 1998) and correspond to the formation of the most recent supercontinents (Pangea 0.2, Gondwana 0.6, \footnotetext{
1. Department of Earth, Environmental and Planetary Sciences, Brown University, Providence, RI, USA
* Corresponding author (email: stephen_parman@brown.edu)
}

Rhodinia $1.2 \mathrm{Ga}$ ). Based upon this, the peaks at 1.9 (Nuna), 2.7 (Superia) and 3.3 (Vaalbara) have also been proposed to be associated with supercontinents (Evans, 2013).

The fundamental question is whether the age peaks mostly reflect variations in CC production rates or are mainly the result of varying destruction rates. The $\mathrm{U}-\mathrm{Pb}$ ages record the time of crystallisation of the zircon, but not whether it was formed by new volumes of crust or by reworking of existing crust. If the number of zircons within a given age range are proportional to the amount of new (juvenile) crust being added at that time, then the peaks and troughs suggest major variations in crustal formation rates. This line of reasoning has led to fundamentally punctuated models of Earth evolution, involving large mantle overturn events and even cessation of plate tectonics (Condie, 1998; Rino et al., 2004; Lowe and Tice, 2007; O’Neill et al., 2007; Pearson et al., 2007; Arndt and Davaille, 2013).

However, connecting the number of zircons to crustal production rates is not straightforward. Decreased numbers of zircons at a given age (troughs in histograms) could be the results of erosion and/or metamorphic processes, or simply due to incomplete sampling (Armstrong, 1991). The age peaks could also reflect times of reduced destruction (greater preservation), rather than variations in additions of new volume to the CC (Belousova et al., 2010; Hawkesworth et al., 2010; Cawood et al., 2012). Also, because metamorphism can produce new zircons (reworking), increases in orogenic continental collisions could produce a spike in zircon formation without adding new CC volume (Hawkesworth et al. 2010; Cawood et al., 2012). This would also produce the observed correlations with tectonic cycles. Studies of Hf isotopes in zircons have generally suggested such processes are the dominant control on the U-Pb age spectrum (Belousova et al., 2010; Hawkesworth et al., 2010; Dhuime et al., 2012).

Here I examine the U-Pb age spectra of detrital zircons as a function of the time at which the zircons were incorporated into sediments (time-lapse analysis; see Methods section in Supplementary Information for details). In essence, this provides a time-lapse movie of CC evolution and the age-old contest between growth and destruction. This requires a large number of analyses, and to my knowledge has only been performed on a database of Australian zircons (Hawkesworth et al, 2010). A recent compilation contains over 200,000 detrital zircon U-Pb ages (Voice et al., 2011), providing the opportunity to do the timelapse analyses on a global scale. A key point about the time-lapse analysis is that it minimises many biases that may exist in the zircon record. Each new rearrangement of continental blocks formed during the supercontinent cycle produces a different spatial distribution of crustal blocks. So rivers sampling older supercontinents should not be subject to the same sampling bias as today's river basins. If they yield the same zircon age spectrum (which they do), then this is quite strong evidence that sampling bias (or incomplete sampling) is not dominating the record. 


\section{Results}

The main result of the time-lapse analysis is that the major $\mathrm{U}-\mathrm{Pb}$ age peaks around 1.2, 1.9 and $2.7 \mathrm{Ga}$, are persistent through time (Figs. 1, 2, online supplementary figures). These age peaks appear prominently in sediments laid down immediately after the age of the peak, and persist in all younger sediments (vertical bands of data in Fig. 2a). Troughs in the data around 2.3 and $1.5 \mathrm{Ga}$ are also persistent (vertical bands with no data in Fig. 2a). Even in sediments formed just after the troughs, no peaks are seen on any continent. The minor peaks at 0.2 and 0.6 also persist in time, but because they are relatively recent, it is difficult to evaluate their long-term evolution. In detail, there is some variation in the age of the $\mathrm{U}-\mathrm{Pb}$ peaks between continents. The peak positions vary on the order of 100-200 Myr (Fig. 2a). For example, the '2.7' Ga peak in Australia actually occurs around $2.5 \mathrm{Ga}$, while in North and Central America it occurs closer to $2.7 \mathrm{Ga}$ (Fig. 1). One can think of it as the Superia age peak band.

Though the peak positions are relatively constant through time, the relative height of the age peaks are not. For the best sampled continents (North America and Australia; Fig. 1), the height of each age peak decreases fairly regularly with sediment age. The result is that in the most recent sediments, there is a general descending pattern in peak heights towards older ages. This is also seen on the other continents. The height of the age peaks should be quite sensitive to sample biasing. Thus in this study, it is peak positions that are primarily interpreted. However, the regularity of the decrease in the age peaks through time is remarkable.

Prior to $3 \mathrm{Ga}$, the $\mathrm{U}-\mathrm{Pb}$ age peaks are not persistent. In general there is only one age peak, which is the same as the age of sediments and evolves through time. The main exception to this is Australia, which has been the subject of intense scrutiny due to the discovery of Hadean zircons in the Jack Hills (Mojzsis et al., 2001; Wilde et al., 2001; Crowley et al., 2005; Harrison et al., 2005; Valley et al., 2005). Mostly based on the Australian data, there is a suggestion of an U-Pb age peak at $\sim 3.3 \mathrm{Ga}$, which largely disappears from the sedimentary record by $\sim 1.5 \mathrm{Ga}$. This is consistent with highly unradiogenic Hf isotope ratios in later Archaean zircons (Kemp et al., 2010).

\section{Discussion}

The time-lapse analysis indicates that the evolution of the CC is fundamentally punctuated. It is unlikely that the troughs at 1.5 and $2.3 \mathrm{Ga}$ in the U-Pb age spectra are due to removal or reworking of large amounts of existing CC. There are no age peaks in these time bands, even in sediments produced shortly after these times. If there were substantial amounts of CC produced (or even reworked) at 1.5 or $2.3 \mathrm{Ga}$, then it had to have been immediately destroyed, so as not to be preserved anywhere, or at any time, in the zircon record. Such selective and complete destruction is improbable and inconsistent with our

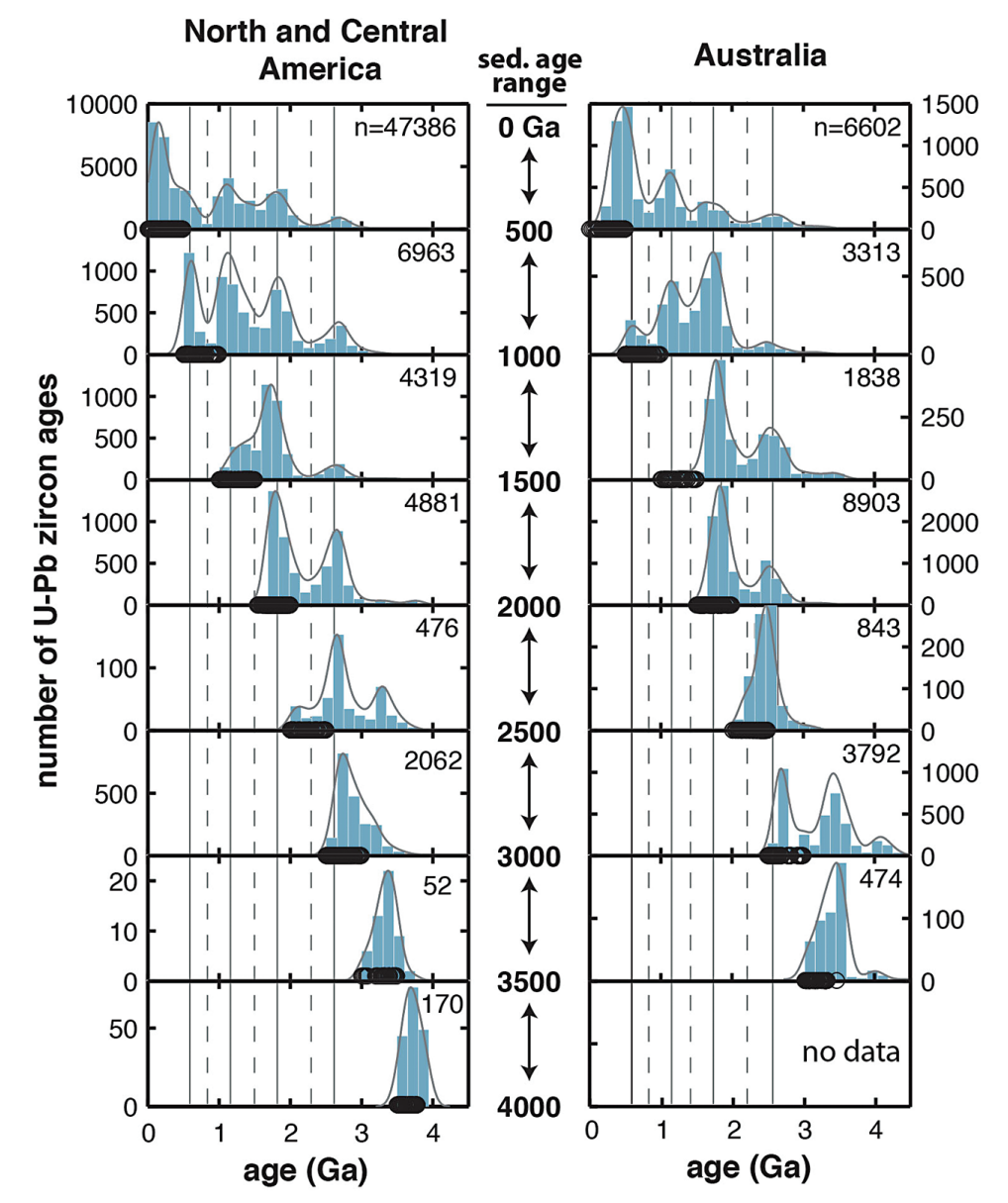

Figure 1 Frequency of U-Pb crystallisation ages in detrital zircons from North + Central America and Australia as a function of the age of the sediment in which they were found (different panels). Data from Voice et al. (2011). Each panel shows a histogram of zircon ages from sediments deposited during a $500 \mathrm{Myr}$ interval, starting from $4000 \mathrm{Ma}$ at the bottom and becoming younger upwards in the figure. Moving from bottom to top, each panel can be viewed as a snapshot in a time-lapse movie of crustal age distribution. For each sediment age interval, both a histogram of the U-Pb ages (blue, scale on $y$-axis) and a kernel density function (grey curves, kernel width $=100 \mathrm{Myr}$ ) are shown. Sediment ages are the reported minimum each bin is shown in upper right hand corner of each panel. The sediment age range is also shown between the two panels. Reference lines are shown for peaks (solid lines) and troughs (dashed). These peaks and troughs persist in sediments of all ages and on all continents (see Figs. S-1 and S-2) indicating that destruction of pre-existing crust did not produce the age peaks or troughs. 


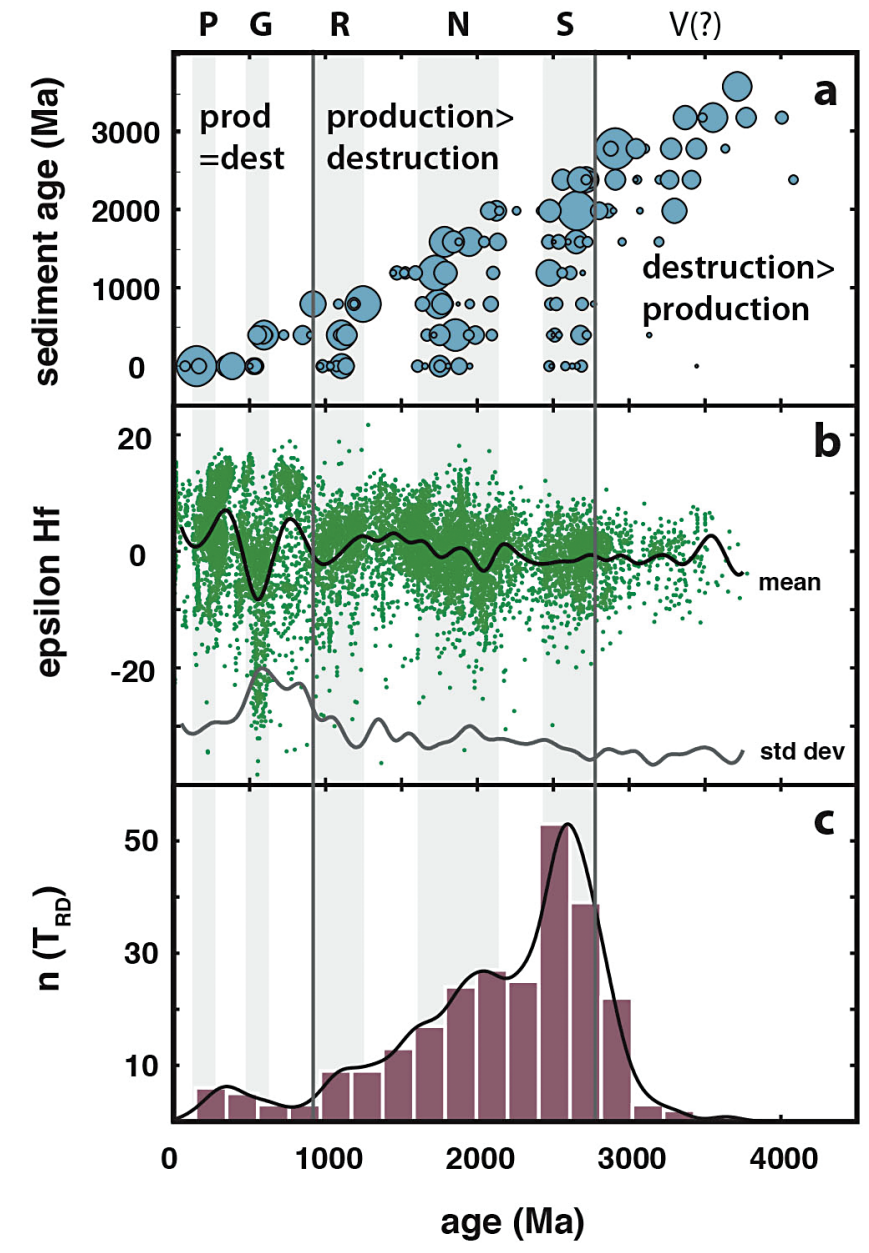

Figure 2 Comparison of zircon $\mathrm{U}-\mathrm{Pb}$ ages and $\mathrm{Hf}$ isotopic compositions with Re depletion ages of mantle xenoliths. (a) Positions of U-Pb zircon age peaks (blue circles) as a function of the age of the sediment in which they were found (sediment age interval $=400 \mathrm{Myr}$ ). The size of the circle is scaled to the height of the peak, times the number of zircons in each sediment interval, to give an indication of the robustness of the peak (see Fig. S-4 for an unscaled version). The vertical bands of dots (highlighted by grey bands) correspond to times of super continent formation: Pangea (P), Gondwana (G), Rodinia (R), Nuna (N), Superia (S) and Vaalbara (V). Only a few small age peaks are found around 1.5 and $2.3 \mathrm{Ga}$, indicating that little continental crust of this age ever existed. See Methods in Supplementary Information for discussion. (b) Epsilon $\mathrm{Hf}$ of zircons versus zircon crystallisation age (data from Belousova et al., 2010). Running mean (black line) and standard deviation (grey line) are also shown (window for averaging $=100 \mathrm{Myr}$ ). Note the lack of large variations in either the mean or standard deviations until after $1 \mathrm{Ga}$. (c) Histogram (red bars) of Re depletion age of mantle xenoliths showing that highly depleted lithosphere formation rates were highest around $2.7 \mathrm{Ga}$ and decreased to near zero by $\sim 1 \mathrm{Ga}$ (data from Pearson et al., 2007). The evolution of the continents is divided into three time periods: destruction rates $>$ growth rates $(4.5-3 \mathrm{Ga})$, growth rates $>$ destruction rates $(3-1 \mathrm{Ga})$ and growth rates $=$ destruction (1 Ga - present), see text and Figure 3 for discussion. The boundaries at 1 and $3 \mathrm{Ga}$ correspond to the major changes in rates of depleted mantle lithosphere formation.

understanding of plate tectonics. The implication is that these were times of globally low (but not zero) CC growth, as is the case today (Clift et al., 2009). The corollary is that the $\mathrm{U}-\mathrm{Pb}$ age peaks were times of higher crustal growth rates, whether by enhanced magmatic additions or by a decrease in destruction (increase in preservation), or some combination of both. Regardless of which it is, the U-Pb zircon record indicates that the growth of the CC is fundamentally non-uniformitarian, punctuated by a few large $\mathrm{CC}$ growth events with durations of 200-400 Myr that appear to coincide with the formation of supercontinents (Evans, 2013). Continents are not the random survivors of plate tectonics (Armstrong, 1991), but were produced by distinct processes at distinct times. The key question then is what are the competing roles of production and destruction in the varying growth rate of the CC.

Based upon Hf isotope ratios in zircons, a number of recent studies have concluded that variations in preservation (destruction) rates associated with formation of super- continents is the main cause of episodic crustal growth (Belousova et al., 2010; Hawkesworth et al., 2010; Kemp et al., 2010; Dhuime et al., 2012; Roberts, 2012). However, calculation of the Hf model-ages used in these studies requires a number of assumptions, primarily that the Hf isotope composition of the zircon has not been contaminated by older crust. While $\mathrm{O}$ isotopes have been used in some studies to try to screen the zircons for such contamination, due to the hyperbolic mixing between $\mathrm{O}$ (a major element) and Hf (a trace element), it is still unclear to what extent Hf model ages represent juvenile crust additions or hybrid ages (Arndt and Davaille, 2013; Roberts and Spencer, 2014).

In general, $\mathrm{Hf}$ ratios in zircons should reflect varying amounts of incorporation of pre-existing, unradiogenic CC. Greater reworking of older crust should produce a decrease in mean Hf isotope ratios of zircons of a given age and a greater dispersion in their Hf isotopic ratios. This appears to be what happened during the 0.6 Ga (Gondwana) age peak (Fig. 2b). But for the 1.2, 1.9 and 2.7 Ga peaks, the mean $\mathrm{Hf}$ and its standard deviation do not vary substantially. Of course, the ingrowth of radiogenic Hf was less at that time, and so ratios should inherently vary less. Even considering this, the abrupt rise of Hf variation after $1 \mathrm{Ga}$ is striking. The data are consistent with an increase in reworking rates after $1 \mathrm{Ga}$

The lack of persistent $\mathrm{U}-\mathrm{Pb}$ age peaks prior to $3 \mathrm{Ga}$ suggests that during this period, destruction rates were higher than crust growth rates, such that little crust was accumulated, consistent with recent Hf isotopic studies of Hadean 
zircons (Kemp et al., 2010). The short-lived 3.3 Ga age peak may reflect destruction rates falling to near crustal growth rates. The change in CC growth at $3 \mathrm{Ga}$ coincides with the formation of stable cratonic mantle (Fig. 2c; Pearson et al., 2007) and a change in the types of mantle inclusions found in diamonds (Shirey and Richardson, 2011). It may be that the falling crustal destruction rates were linked to the formation of stable cratonic platforms on which the crust could be preserved against plate tectonic processing (Korenaga, 2013).

A speculative model of CC evolution is shown in Figure 3. Though nonunique, the model is consistent with the $\mathrm{U}-\mathrm{Pb}$ ages and $\mathrm{Hf}$ isotopic composition of detrital zircons and with the Os isotope composition of highly depleted

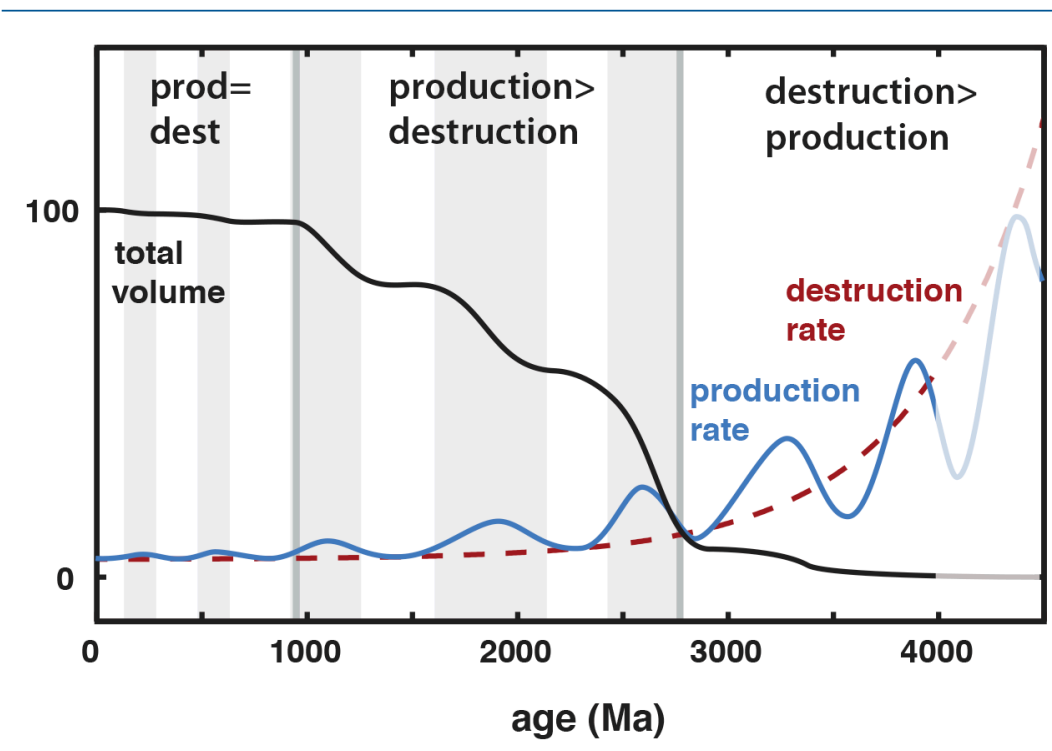

Figure 3 Schematic model of continental growth consistent with the zircon U-Pb and $\mathrm{Hf}$ data. The lack of a scale bar on the $y$-axis indicates that the model shown here is speculative and should not be taken as quantitative. Hypothetical rates of continent growth (blue solid line) and destruction (red dashed line) are shown as exponentially decreasing (assuming the early Earth was hotter and mantle convection/melting was more vigorous), with the growth rate oscillating. Destruction (preservation) rates probably also varied, but are not shown for clarity. The black line indicates cumurative crustal volume starting at 0 and ending at the present day volume. Prior to $3 \mathrm{Ga}$, destruction outpaces growth and little continental volume is preserved. Prior to $4 \mathrm{Ga}$ (faded lines), no crust is preserved, other than as detrital zircons. The hypothesis suggested here is that the decrease in destruction rates was faster than crustal growth rates, such that at $\sim 3 \mathrm{Ga}$, growth outpaces destruction and significant volumes of continental crust can be preserved. This corresponds to the formation of highly depleted mantle (Fig. 2c) and possibly to the onset of plate tectonics. By $\sim 1 \mathrm{Ga}$, both growth and destruction rates may have fallen to minimal values, producing little net crustal growth. Reworking of existing crust becomes the dominant zircon-producing process, as suggested by the large variations in zircon $\mathrm{Hf}$ isotopic composition after $1 \mathrm{Ga}$. Grey bands are taken from Figure 2 . mantle. The hypothesis is that the competition between production and destruction has changed over time, with destruction dominating prior to $3 \mathrm{Ga}$, production dominating between 3 and $1 \mathrm{Ga}$ and reworking dominating after $1 \mathrm{Ga}$, when both production and destruction rates fell to low values. Production and destruction rates prior to $3 \mathrm{Ga}$ are completely speculative, but based on the general concept that the Earth would be hotter at that time and so the mantle would be convecting faster, possibly causing high crustal production and destruction rates. Whatever the case, the absence of crust older than $4 \mathrm{Ga}$ (so far) is prima facia evidence that destruction rates were faster than production rates, whatever the form or absolute rates were. In this hypothesis, crustal production, destruction and reworking occurred at all times, but varied in their relative rates. The changes in crustal evolution at 1 and $3 \mathrm{Ga}$ correspond to the changes in the age spectrum (presumably representative of production rates) of the highly depleted mantle (Fig. 2c), and suggest the evolution of the two may be intimately linked. The general evolution of crustal evolution from high to low production and destruction rates is consistent with the secular cooling of the Earth's interior (Korenaga, 2013), while the non- uniformitarian nature of CC evolution suggests that the Earth's heat loss has also been punctuated (O’Neill et al., 2007)

\section{Acknowledgements}

Peter Voice is thanked for constructing such an excellent and extensive database. Comments by Peter and two anonymous reviewers improved the manuscrip substantially.

Editor: Graham Pearson

\section{Additional Information}

Supplementary Information accompanies this letter at www.geochemicalperspectivesletters.org/article1505

Reprints and permission information is available online at http://www. geochemicalperspectivesletters.org/copyright-and-permissions

Cite this letter as: Parman, S.W. (2015) Time-lapse zirconography: Imaging punctuated continental evolution. Geochem. Persp. Let. 1, 43-52.

\section{References}

ARMSTRONG, R.L. (1991) The persistent myth of crustal growth. Australian Journal of Earth Sciences $38,613-630$

ARnDt, N., Davaille, A. (2013) Episodic Earth evolution. Tectonophysics 609, 661-674. 
Barley, M.E., BeKKER, A., KRAPeZ, B. (2005) Late Archean to Early Paleoproterozoic global tectonics, environmental change and the rise of atmospheric oxygen. Earth and Planetary Science environmental chan
Letters 238, 156-171.

Belousova, E.A., Kostitsyn, Y.A., Griffin, W.L., BegG, G.C., O’Reilly, S.Y. Pearson, N.J. (2010) The growth of the continental crust: Constraints from zircon Hf-isotope data. Lithos

Bowring, S.A., Housh, T. (1995) The Earth early evolution. Science 269, 1535-1540.

CAWOOD, P.A., HAWKesWorth, C.J., DHUIME, B. (2012) Detrital zircon record and tectonic setting. Geology 40, 875-878

CLIFT, P.D., VANNuCCHI, P., MORGAN, J.P. (2009) Crustal redistribution, crust-mantle recycling and Phanerozoic evolution of the continental crust. Earth-Science Reviews 97, 80-104.

CONDIE, K.C. (1998) Episodic continental growth and supercontinents: a mantle avalanche connection? Earth and Planetary Science Letters 163, 97-108.

Condie, K.C., KRoENER, A. (2013) The building blocks of continental crust: Evidence for a major change in the tectonic setting of continental growth at the end of the Archean. Gondwana Research 23, 394-402.

Condie, K.C., Bickford, M.E., Aster, R.C., Belousova, E., Scholl, D.W. (2011) Episodic zircon ages, Hf isotopic composition, and the preservation rate of continental crust. Geological Society of America Bulletin 123, 951-957.

Crowley, J.L., Myers, J.S., Sylvester, P.J., Cox, R.A. (2005) Detrital zircon from the Jack Hills and Mount Narryer, Western Australia: Evidence for diverse > 4.0 Ga source rocks. Journal of Geology 113, 239-263.

Dhuime, B., HaWkesworth, C.J., CaWood, P.A., Storey, C.D. (2012) A change in the geodynamics of continental growth 3 billion years ago. Science $335,1334-1336$

Evans, D.A.D. (2013) Reconstructing pre-Pangean supercontinents. Geological Society of America Bulletin 125, 1735-1751.

Harrison, T.M., Blichert-Toft, J., Muller, W., Albarède, F., Holden, P. Mojzsis, S.J. (2005) Heterogeneous Hadean hafnium: Evidence of continental crust at 4.4 to 4.5 Ga. Science 310, 1947-1950.

Hawkesworth, C.J., Dhuime, B., Pietranik, A.B., Cawood, P.A., Kemp, A.I.S., Storey, C.D. (2010) The generation and evolution of the continental crust. Journal of the Geological Society 167, 229-248.

Kemp, A.I.S., Wilde, S.A., Hawkesworth, C.J., Coath, C.D., Nemchin, A., Pidgeon, R.T., Vervoort, J.D., DuFrane, S.A. (2010) Hadean crustal evolution revisited: New constraints from Pb-Hf isotope systematics of the Jack Hills zircons. Earth and Planetary Science Letters 296, 45-56.

KoRENAGA, J. (2013) Initiation and evolution of plate tectonics on Earth: Theories and observations. Annual Review of Earth and Planetary Sciences 41, 117-151.

LowE, D.R., TicE, M.M. (2007) Tectonic controls on atmospheric, climatic, and biological evolution 3.5-2.4 Ga. Precambrian Research 158, 177-197.

Mojzsis, S.J., HarRIson, T.M., Pidgeon, R.T. (2001) Oxygen-isotope evidence from ancient zircon for liquid water at the Earth's surface 4,300 Myr ago. Nature 409, 178-181.

O'Neill, C., Lenardic, A., Moresi, L., TorsviK, T.H., Lee, C.T.A. (2007) Episodic Precambrian subduction. Earth and Planetary Science Letters 262, 552-562.

Pearson, D.G., Parman, S.W. Nowell, G.M. (2007) A link between large mantle melting events and continent growth seen in osmium isotopes. Nature 449, 202-205.

Rino, S., Komiya, T., Windley, B.F., Katayama, I., Motoki, A., Hirata, T. (2004) Major episodic increases of continental crustal growth determined from zircon ages of river sands, implications for manteove

ROBERTS, N.M.W. (2012) Increased loss of continental crust during supercontinent amalgamation. Gondwana Research 21, 994-1000.

RoberTS, N.M., SPEnCER, C.J. (2014) The zircon archive of continent formation through time Geological Society, London, Special Publications 389, SP389.14.
SHIREY, S.B., Richardson, S.H. (2011) Start of the Wilson Cycle at 3 Ga Shown by diamonds from Subcontinental Mantle. Science 333, 434-436.

Valley, J.W., Lackey, J.S., Cavosie, A.J., Clechenko, C.C., Spicuzza, M.J., Basei, M.A.S., Bindeman, I.N., Ferreira, V.P., Sial, A.N., King, E.M., Peck, W.H., Sinha, A.K., Wei, C.S. (2005) 4.4 billion years of crustal maturation: oxygen isotope ratios of magmatic zircon. Contrib

Voice, P.J., KowalewsKI, M., ERIKSSON, K.A. (2011) Quantifying the timing and rate of crustal evolution: Global compilation of radiometrically dated detrital zircon grains. Journal of Geology 119, 109-126.

Wilde, S.A., Valley, J.W., Peck, W.H., Graham, C.M. (2001) Evidence from detrital zircons for the existence of continental crust and oceans on the Earth 4.4 Gyr ago. Nature 409, 175-178. 